\title{
Evaluation of MoPyC-prosthesis implantation and the use of angular stable plates in the treatment of comminuted radial head fractures
}

\author{
T.F. Raven ${ }^{\mathrm{a}, \mathrm{b}, *}$, M. Schönewald ${ }^{\mathrm{b}}$, J. Doll ${ }^{\mathrm{b}}$, L. Banken ${ }^{\mathrm{b}}$, G. Schmidmaier ${ }^{\mathrm{b}}$, A. Moghaddam ${ }^{\mathrm{a}, \mathrm{b}}$ \\ ${ }^{\text {a } A T O R G ~-~ A s c h a f f e n b u r g ~ T r a u m a ~ a n d ~ O r t h o p a e d i c ~ R e s e a r c h ~ G r o u p, ~ C e n t e r ~ f o r ~ T r a u m a ~ S u r g e r y, ~ O r t h o p a e d i c s ~ a n d ~ S p o r t s ~ M e d i c i n e, ~ H o s p i t a l ~ A s c h a f f e n b u r g-A l z e n a u, ~ A m ~}$ \\ Hasenkopf 1, D-63739 Aschaffenburg, Germany \\ ${ }^{\mathrm{b}}$ HTRG - Heidelberg Trauma Research Group, Division of Trauma and Reconstructive Surgery, Center for Orthopaedics, Trauma Surgery and Spinal Cord Injury, University \\ Hospital Heidelberg, Schlierbacher Landstraße 200a, D-69118 Heidelberg, Germany
}

\section{A R T I C L E I N F O}

\section{Keywords:}

Radial head

Radial head prosthesis

Radial head plate

Angular stable plate

MoPyC-prosthesis

Locking plate

\begin{abstract}
A B S T R A C T
Objective: Comminuted radial head fractures are disproportionately often accompanied by injuries of the bone or ligaments and can be treated in different ways.

Methods: 15 patients with a comminuted radial head fracture were treated with an angular stable plate (=G1) and 8 with a MoPyC-prosthesis (=G2).

Results: G1 shows an average Morrey-score of 83,87 points. Complications occurred in 5/15 patients. Within G2 an average Morrey-score of 86 was achieved. Complications could be shown in 2/8 patients.

Conclusion: Both the treatment provides a clear individual benefit for the patients and predict promising results for the treatment of comminuted radial head fractures.
\end{abstract}

\section{Introduction}

The radial head is involved in about one-third of all elbow fractures and up to $3 \%$ of all fractures. The mean female patient suffering from such an injury is 50-60 years old. Male patients are younger with an average age of $30-40$. The sex ratio is about $1: 1(\mathrm{w}: \mathrm{m}){ }^{1-4}$

Comminuted radial head fractures often go along with osteoligamental companion injuries. These need to be treated with considerable care in order to obtain satisfying long-term results. The reconstruction of the physiological joint anatomy is paramount to guarantee the recovery of the elbow's radial column.

For simple fractures of the radial head (Mason II), the technique of open reduction and internal fixation (ORIF) has proven to be effective. ${ }^{5}$ Treatment decisions concerning complex fractures (Mason III and IV) are more complicated.

For the latter, endoprosthetic treatment and angular stable plate osteosynthesis have distinguished themselves as treatment concepts the question is whether comparable results can be achieved.

With respect to endoprosthetic treatment, long-term data is missing and possible limitations in functionality need to be taken into consideration. Especially with regard to younger patients, the need for follow-up surgery can be reduced by carefully choosing the initial treatment strategy.
Osteosynthetic reconstruction like ORIF turned out to be difficult, failed on multiple occasions and led to complications such as malfunction of the implant, necrosis of the radial head, pseudarthrosis and limited mobility. ${ }^{6,7}$

The following paper aims at evaluating treatment options implemented in our center - angular stable plate osteosynthesis and endoprosthesis - in order to figure out if one of the two procedures stands out as more effective for complex radial head fractures.

By means of our clinical examination we would like to pursue the following questions:

1. What is the outcome of both collectives considering the indication?

2. Are there injuries for which one of the treatments is completely contraindicated?

3. Are there injuries for which one of the treatments is superior due to the post-surgical outcome?

\subsection{Patients and methods}

From June 2011 until June 2014, 15 patients that were treated with an angular stable plate at our center for orthopaedics, trauma surgery and paraplegiology could be included in our study. ${ }^{8}$ Furthermore, 8 patients treated with a MoPyC-prosthesis (Tornier, Montbonnot-Saint-

\footnotetext{
* Corresponding author. ATORG - Aschaffenburg Trauma and Orthopaedic Research Group, Center for Trauma Surgery, Orthopaedics and Sports Medicine, Hospital Aschaffenburg-Alzenau, Am Hasenkopf 1, D-63739 Aschaffenburg, Germany

E-mail address: dr.raventf@gmail.com (T.F. Raven).
} 
Martin, France) were included.

The average age of patients treated with an angular stable plate was 54 years (median 59; minimum 22 - maximum 84) at the time of the follow-up examination. The average follow-up period was 30 months (29; 17-56). In $7 / 15$ cases the right upper extremity was affected by the injury, in $8 / 15$ cases the left upper extremity was affected. On average the injuries were treated after 1,8 days $(1 ; 0-5)$.

Within the collective of patients treated with a prosthesis the average age was 52 years $(53,5 ; 18-71)$. The average follow-up period was 18 months $(18 ; 14-42)$. In $7 / 8$ cases the right upper extremity was affected by the injury, in $1 / 8$ cases the left upper extremity was affected.

On average the injuries were treated after 2,6 days $(2 ; 0-8)$ within the collective treated with a prosthesis.

The follow-up examination for both groups of patients was done with the help of a standardized follow-up questionnaire, which captured parameters concerning pain, strength and function of the joint as well as possible everyday discomforts.

The evaluation of the results was done with the help of the Morreyscore $^{9}$ as well as the score of Radin and Riseborough. ${ }^{10}$

Because of the international usability, the classification of fractures was done with the help of the Mason-classification, ${ }^{11}$ modified by Broberg and Morrey, ${ }^{12}$ as well as x-ray images in a.p. direction and $\mathrm{x}$ ray images of the radial head after Greenspan. ${ }^{13}$

\subsection{Medical indication of treatment}

Following the concept of our center, radial head fractures which affect more than $1 / 3$ of the articular surface or which show a dislocation of more than $2 \mathrm{~mm}$, are treated surgically.

Mason-2-fractures are normally treated with the help of screws, while Mason-3-fractures as well as Mason-4-fractures are treated with the help of angular stable plates or a prosthesis, in case a reconstruction seems not possible in any other way after careful examination.

Only angular stable plate systems were used. Mainly, implants like the APTUS ${ }^{\circledR}$ - angular stable radial head plate system from Medartis ${ }^{\circledR}$ (Basel, Switzerland) or the DePuy Synthes LCP-locking plate system (Oberndorf, Switzerland) were used.

By default, a.p. X-ray images were taken preoperatively along with lateral X-ray images as well as a Greenspan radial head x-ray image. ${ }^{13}$ For further information concerning possible concomitant injuries of the injured elbow joint, a CT scan was taken, for example to capture a possible fracture of the capitulum.

\subsection{MoPyc prosthesis}

The MoPyC radial head prosthesis is a modular prosthesis with a long shaft that uses the press-fit technique. The shaft of the prosthesis as well as its neck consist of titanium, the head is made of pyrocarbon. In order to enable an optimal reconstruction of the joint anatomy, 3 different sizes of the prosthesis head exist along with 4 different sizes for the shaft as well as for the neck. In total, 48 different combinations are possible. The head of the prosthesis has an angle of $15^{\circ}$ towards the neck of. ${ }^{14}$

\subsection{Postoperative care}

Functional mobilisation was enforced as early as possible. The patients, who had a refixation of the collateral ligament, were instructed to avoid varus and valgus stress for 6 weeks. A dorsal splint was applied to limit the extension of the elbow, if a refixation of the processus coronoideus was indicated. To prevent periarticular ossifications, all patients were medicated with Voltaren ${ }^{\circ}$ Resinat $75 \mathrm{mg}$ (Voltaren"; Novartis, Basel, Switzerland) for 4 weeks postoperatively. A sufficient gastric mucosa protection was implemented beforehand.

\subsection{X-ray examination}

The evaluation of the $\mathrm{x}$-ray images was done by two independent trauma surgeons of our center. X-ray images of the accident and followup x-ray images were used for the evaluation. We especially focused on aspects like the location of the implant, possible humeroulnar arthrosis, loss of reduction or loosening as well as failing of the implant when evaluating the images.

With the help of the classification by Brooker, ${ }^{15}$ we evaluated the periarticular ossification.

\subsection{Ethics committee vote and data}

This study was approved by the ethics committee of the Medical Faculty of the University of Heidelberg (No. S-531/2011). The study design and patient inclusion follows the declaration of Helsinki in its present form. The analysis of the data was performed using Microsoft Office Excel $^{\circ} 2016$ and IBM SPSS ${ }^{\circ}$ Statistics 24. Data is shown as mean value, median and range.

\section{Results}

\subsection{Results of the collective treated with angular stable plates (G1)}

Within G1, 7/15 patients suffered a direct trauma of the elbow joint and 4/15 patients each fell frontwards or backwards on the outstretched arm.

Most commonly patients suffered the trauma while doing sports or leisure activities $(6 / 15)$, equally frequent were traumas at work or on the way to work (6/15). $3 / 15$ patients suffered a trauma in their domestic environment.

On average, patients were treated operatively 1,8 days $(0,0,1,1-5)$ after suffering the trauma. Postoperative exercises were started after 1,93 days. $(1 ; 1-14)$

For range of motion see Table 1 and Fig. 1.

The circumferences of the upper arm and the forearm of the affected side did not differ from the ones of the opposite side at the date of postoperative reexamination.

The measurement of the possible force was done with the help of a Jamar ${ }^{\circledR}$-hand-dynamometer. The maximum power of the affected extremity was on average $19,7 \mathrm{~kg}(20 ; 1-35)$ compared to $23,2 \mathrm{~kg}(20$; 10-40) of the opposite side.

\subsection{Score evaluation of the collective treated with angular stable plates} (G1)

The evaluation of the Morrey-score ${ }^{9}$ within G1 showed that 2/15 patients were rated as excellent, 10/15 were rated as good and 3/15

Table 1

Results of the follow-up examination after treatment with angular stable plates (G1).

\begin{tabular}{lll}
\hline \multicolumn{2}{l}{ Average (Median; Minimum - Maximum) } & \\
\hline & Affected extremity & Opposite extremity \\
\hline Flexion of the elbow joint & $119^{\circ}\left(122^{\circ} ; 90^{\circ}-140^{\circ}\right)$ & $129,3^{\circ}\left(130^{\circ} ; 95^{\circ}-140^{\circ}\right)$ \\
Lack of extension & $12,7^{\circ}\left(10^{\circ} ; 0^{\circ}-30^{\circ}\right)$ & $0^{\circ}\left(0^{\circ} ;-5^{\circ}-+5^{\circ}\right)$ \\
Supination & $59,3^{\circ}\left(70^{\circ} ; 5^{\circ}-90^{\circ}\right)$ & $84^{\circ}\left(80^{\circ} ; 70^{\circ}-90^{\circ}\right)$ \\
Pronation & $71^{\circ}\left(80^{\circ} ; 10^{\circ}-90^{\circ}\right)$ & $83,7^{\circ}\left(90^{\circ} ; 70^{\circ}-95^{\circ}\right)$ \\
Cubitus valgus & $6,7^{\circ}\left(10^{\circ} ; 0^{\circ}-15^{\circ}\right)$ & $4,7^{\circ}\left(5^{\circ} ; 0^{\circ}-10^{\circ}\right)$ \\
Strength in kg & $19,7 \mathrm{~kg}(20 \mathrm{~kg} ; 1 \mathrm{~kg}-$ & $23,2 \mathrm{~kg}(20 \mathrm{~kg} ; 10 \mathrm{~kg}-$ \\
& $35 \mathrm{~kg})$ & $40 \mathrm{~kg})$ \\
Flexion of the wrist & $52,7^{\circ}\left(60^{\circ} ; 20^{\circ}-75^{\circ}\right)$ & $55,3^{\circ}\left(60^{\circ} ; 40^{\circ}-75^{\circ}\right)$ \\
Extension of the wrist & $56,7^{\circ}\left(60^{\circ} ; 30^{\circ}-80^{\circ}\right)$ & $59,7^{\circ}\left(60^{\circ} ; 30^{\circ}-80^{\circ}\right)$ \\
Radial abduction & $23,3^{\circ}\left(20^{\circ} ; 10^{\circ}-30^{\circ}\right)$ & $25,7^{\circ}\left(25^{\circ} ; 20^{\circ}-30^{\circ}\right)$ \\
Ulnar abduction & $33,7^{\circ}\left(40^{\circ} ; 10^{\circ}-40^{\circ}\right)$ & $37^{\circ}\left(40^{\circ} ; 30^{\circ}-40^{\circ}\right)$ \\
\hline
\end{tabular}




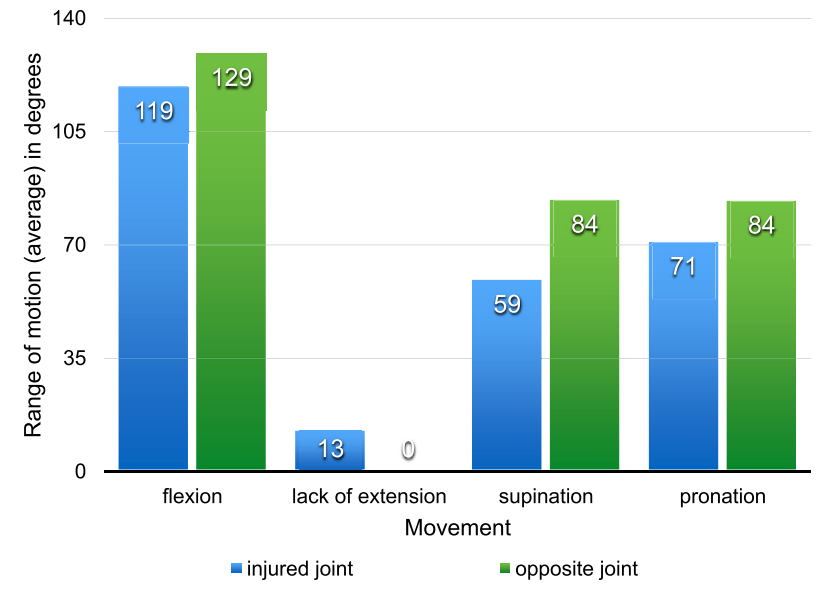

Figure 1. Range of motion after treatment with angular stable plates.

Table 2

Treatment outcome considering the Morrey-criteria in dependence on the fracture type after treatment with angular stable plates (G1).

\begin{tabular}{llll}
\hline Morrey-Score & Mason II & Mason III & Mason IV \\
\hline Excellent & 0 & 1 & 1 \\
Good & 1 & 3 & 6 \\
Acceptable & 0 & 1 & 2 \\
Inadequate & 0 & 0 & 0 \\
Total & 1 & 5 & 9 \\
\hline
\end{tabular}

patients were rated as acceptable. None of the patients had to be rated as inadequate (Table 2).

On average, G1 reached a Morrey-score of 83,87 points $(82,8$; 53,5-100).

Radin \& Riseborough score ${ }^{10}$ is shown in Table 3. Accompanying injuries of G1 are shown in Table 4.

When comparing the Mason fracture types using the score of Radin \& Riseborough, ${ }^{10}$ it can be found that the one Mason-II-fracture has to be rated as acceptable, the 5 Mason-III-fractures can be rated as good in $3 / 5$ cases, as acceptable in $1 / 5$ cases and as poor in $1 / 5$ cases (Table 3). The 9 Mason-IV-fractures are rated as good in 3/9 cases, as acceptable in $3 / 9$ cases and as poor in $3 / 9$ cases.

\subsection{Complications within the collective treated with angular stable plates (G1)}

Two cases of implant failure were reported, namely one case of plate fracture and one case of a dislocation of a screw into the intra-articular space. Furthermore, three cases of radial head necrosis were reported in two cases a MoPyC-prosthesis was implanted, in one case a total elbow prosthesis was applied. The rest of the patients (10/15) showed satisfying results regarding the consolidation of the bone.

No case of a humeroulnar arthrosis was documented.

Subjective and functional outcome is shown in Table 5 .

Posttraumatically, one patient showed a highly limited range of

Table 3

Treatment outcome considering the Radin \& Riseborough criteria in dependence on the fracture type after treatment with angular stable plates (G1).

\begin{tabular}{llll}
\hline $\begin{array}{l}\text { Results considering Radin \& Riseborough } \\
\text { criteria }\end{array}$ & Mason II & Mason III & Mason IV \\
\hline Good & 0 & 3 & 3 \\
Acceptable & 1 & 1 & 3 \\
Poor & 0 & 1 & 3 \\
Total & 1 & 5 & 9 \\
\hline
\end{tabular}

Table 4

Overview of accompanying injuries after treatment with angular stable plates (G1)

\begin{tabular}{|c|c|c|}
\hline & $\begin{array}{l}\text { number } \\
(\mathrm{n}=15)\end{array}$ & percentage rates \\
\hline Patients with accompanying injuries & 14 & $93,3 \%$ \\
\hline Rupture of the proc. coronoideus & 10 & $66,7 \%$ \\
\hline $\begin{array}{l}\text { Luxation of the elbow with rupture of the } \\
\text { proc. coronoideus }\end{array}$ & 8 & $53,3 \%$ \\
\hline $\begin{array}{l}\text { Luxation of the elbow without rupture of the } \\
\text { proc. coronoideus }\end{array}$ & 1 & $6,7 \%$ \\
\hline Injuries of the radial collateral ligament & 10 & $66,7 \%$ \\
\hline Injuries of the ulnar collateral ligament & 9 & $60 \%$ \\
\hline Injuries of the ventral capsula & 13 & $86,7 \%$ \\
\hline Fractures of the olecranon & 0 & $0 \%$ \\
\hline Monteggia-like lesions & 1 & $6,7 \%$ \\
\hline Essex-Lopresti-lesions & 1 & $6,7 \%$ \\
\hline
\end{tabular}

Table 5

Subjective opinion of patients.

\begin{tabular}{|c|c|c|}
\hline Pain at the time of the follow-up examination & $\mathrm{G} 1(\mathrm{n}=15)$ & $\mathrm{G} 2(\mathrm{n}=8)$ \\
\hline none & 7 & 2 \\
\hline moderate & 7 & 6 \\
\hline severe & 1 & 0 \\
\hline total & 15 & 8 \\
\hline Frequency of pain & G1 $(n=15)$ & G2 $(n=8)$ \\
\hline permanent & 0 & 0 \\
\hline regular & 5 & 1 \\
\hline occasional & 4 & 4 \\
\hline rare & 6 & 3 \\
\hline total & 15 & 8 \\
\hline loss of strength & 11 & 6 \\
\hline Subjective satisfaction with the postoperative result & G1 $(n=15)$ & G2 $(n=8)$ \\
\hline very satisfied & 4 & 4 \\
\hline good & 6 & 2 \\
\hline acceptable & 5 & 2 \\
\hline dissatisfied & 0 & 0 \\
\hline total & 15 & 8 \\
\hline \multicolumn{3}{|l|}{ Functional outcome of patients } \\
\hline discomfort during daily routine & G1 $(n=15)$ & G2 $(n=8)$ \\
\hline no limitations & 13 & 5 \\
\hline $\begin{array}{l}\text { lowgrade limitations and protection of the affected } \\
\text { extremity }\end{array}$ & 1 & 2 \\
\hline job changing & 1 & 1 \\
\hline retirement during the time of the injury & 4 & 3 \\
\hline Incapacity for work $<6$ months & 10 & 3 \\
\hline Incapacity for work $>12$ months & 1 & 2 \\
\hline discomforts of the wrist of the affected extremity & G1 $(n=15)$ & G2 $(n=8)$ \\
\hline limitation of the movement of fingers & 1 & 2 \\
\hline $\begin{array}{l}\text { Lack of strength of the hand on the affected } \\
\text { extremity }\end{array}$ & 5 & 3 \\
\hline Pain concerning the wrist & $\mathbf{G 1} \mathbf{f}(\mathbf{n}=15)$ & G2 $(n=8)$ \\
\hline under heavy physical stress & 1 & 1 \\
\hline under moderate physical stress & 1 & 0 \\
\hline at rest & 2 & 2 \\
\hline no pain & 11 & 5 \\
\hline
\end{tabular}

motion, mainly concerning the pronation and supination. The maximum of pronation was $10^{\circ}$ and the maximum of supination was $5^{\circ}$. With this patient, postoperative training was started one day after the surgical intervention.

Furthermore, 2/15 patients suffered neurological damage including hypaesthesia of the fingers. None of the patients showed radial nerve palsy.

\subsection{Results of the collective treated with MoPyC-prosthesis (G2)}

Within G2, 4/8 patients suffered a direct trauma of the elbow joint and $2 / 8$ patients each fell frontwards or backwards on the outstretched arm.

Most commonly, patients suffered the trauma while doing sports or 
Table 6

Results of the follow-up examination after treatment with MoPyC-prosthesis (G2).

\begin{tabular}{lll}
\hline Average (Median; Minimum - Maximum) & \\
\hline & Affected extremity & Opposite extremity \\
\hline Flexion of the elbow & $124^{\circ}\left(125^{\circ} ; 100^{\circ}-140^{\circ}\right)$ & $133^{\circ}\left(132,5^{\circ} ; 120^{\circ}-140^{\circ}\right)$ \\
Lack of extension & $18^{\circ}\left(10^{\circ} ; 5^{\circ}-45^{\circ}\right)$ & $0^{\circ}\left(0^{\circ} ; 0^{\circ}-0^{\circ}\right)$ \\
Supination & $73,75^{\circ}\left(80^{\circ} ; 30^{\circ}-90^{\circ}\right)$ & $85^{\circ}\left(85^{\circ} ; 80^{\circ}-90^{\circ}\right)$ \\
Pronation & $75^{\circ}\left(85^{\circ} ; 10^{\circ}-100^{\circ}\right)$ & $88^{\circ}\left(90^{\circ} ; 80^{\circ}-100^{\circ}\right)$ \\
Cubitus valgus & $2,5^{\circ}\left(0^{\circ} ; 0^{\circ}-10^{\circ}\right)$ & $1,88^{\circ}\left(0^{\circ} ; 0^{\circ}-10^{\circ}\right)$ \\
Strength in kg & $19,9 \mathrm{~kg}(20,5 \mathrm{~kg} ; 10 \mathrm{~kg}-$ & $25,1 \mathrm{~kg}(25 \mathrm{~kg} ; 15 \mathrm{~kg}-$ \\
& $30 \mathrm{~kg})$ & $35 \mathrm{~kg})$ \\
Flexion of the wrist & $58,1^{\circ}\left(55^{\circ} ; 45^{\circ}-80^{\circ}\right)$ & $59,4^{\circ}\left(57,5^{\circ} ; 45^{\circ}-80^{\circ}\right)$ \\
Extension of the wrist & $53,8^{\circ}\left(55^{\circ} ; 40^{\circ}-70^{\circ}\right)$ & $54,4^{\circ}\left(55^{\circ} ; 40^{\circ}-70^{\circ}\right)$ \\
Radial abduction & $26,9^{\circ}\left(30^{\circ} ; 15^{\circ}-35^{\circ}\right)$ & $27,5^{\circ}\left(30^{\circ} ; 15^{\circ}-35^{\circ}\right)$ \\
Ulnar abduction & $31,9^{\circ}\left(30^{\circ} ; 15^{\circ}-45^{\circ}\right)$ & $31,9^{\circ}\left(30^{\circ} ; 15^{\circ}-45^{\circ}\right)$
\end{tabular}

leisure activities (5/8), followed by $3 / 8$ patients who suffered the trauma in their domestic environment.

On average, patients received operational treatment 2,6 days $(2 ; 0-$ 8 ) after the trauma and postoperative exercises were started in mean 2,6 days $(1 ; 1-12)$ after the operation.

The range of motion is shown in Table 6 and Fig. 2.

The circumference of the upper arm as well as the forearm of the affected side of the body did not differ from the other side.

With the affected extremity, patients could achieve an average maximum power of $19,9 \mathrm{~kg}(20,5 ; 10-30)$ compared to an average maximum power of $25,1 \mathrm{~kg}(25 ; 15-35)$ with the opposite extremity. (G2).

Score evaluation of the collective treated with MoPyC-prosthesis

The evaluation of the Morrey-score ${ }^{9}$ within G2 showed that $1 / 8$ patients was rated as excellent, $6 / 8$ patients were rated as good and $1 / 8$ patients was rated as acceptable. None of the patients had to be rated as inadequate (Table 7).

On average, G2 reached a Morrey score ${ }^{9}$ of 86 points $(87 ; 70-98)$.

The Radin \& Riseborough score ${ }^{10}$ is shown in Table 8. Accompanying injuries are shown in Table 9 (see Table 9).

When comparing the Mason fracture types using the score of Radin \& Riseborough, ${ }^{10}$ it can be found that the Mason-III-fracture has to be rated as poor, while the seven Mason-IV-fractures can be rated as good in $2 / 7$ cases, as acceptable in $3 / 7$ cases and as poor in $2 / 7$ cases (Table 8).

\subsection{Complications within the collective treated with prosthesis (G2)}

2/8 cases of implant failure were reported, namely one case in which the implantation of the prosthesis neck was too short, leading to

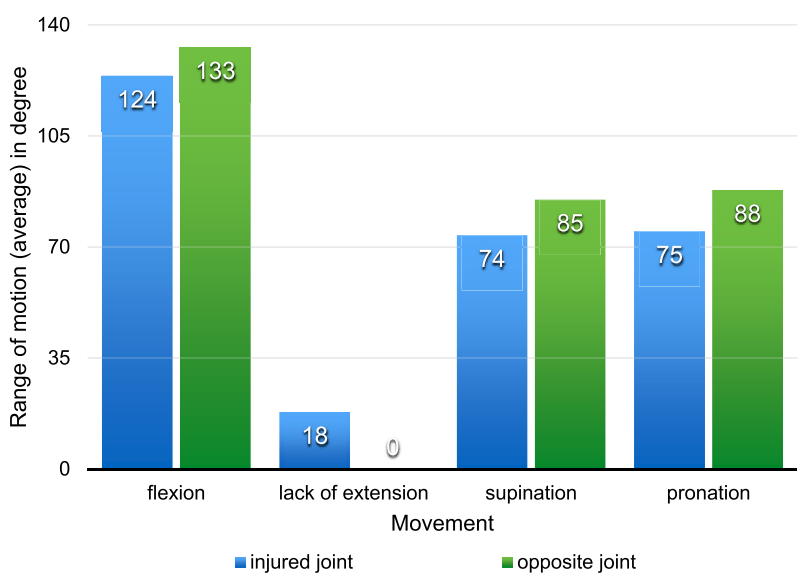

Figure 2. Range of motion after treatment with MoPyc-Prosthesis.
Table 7

Treatment outcome considering the Morrey-criteria in dependence on the fracture type after implantation of MoPyC-prosthesis (G2).

\begin{tabular}{llll}
\hline Morrey-Score & Mason II & Mason III & Mason IV \\
\hline Excellent & 0 & 0 & 1 \\
Good & 0 & 1 & 5 \\
Acceptable & 0 & 0 & 1 \\
Inadequate & 0 & 0 & 0 \\
Total & 0 & 1 & 7 \\
\hline
\end{tabular}

Table 8

Treatment outcome considering the Radin \& Riseborough criteria in dependence on the fracture type after MoPyC-prosthesis implantation (G2).

\begin{tabular}{llll}
$\begin{array}{l}\text { Results considering Radin \& Riseborough } \\
\text { criteria }\end{array}$ & Mason II & Mason III & Mason IV \\
\hline Good & 0 & 0 & 2 \\
Acceptable & 0 & 0 & 3 \\
Poor & 0 & 1 & 2 \\
Total & 0 & 1 & 7 \\
\hline
\end{tabular}

Table 9

Overview over accompanying injuries after treatment with MoPyC-prosthesis (G2).

\begin{tabular}{|c|c|c|}
\hline & $\begin{array}{l}\text { number } \\
(\mathrm{n}=8)\end{array}$ & percentage rates \\
\hline Patients with accompanying injuries & 8 & $100 \%$ \\
\hline Rupture of the proc. coronoideus & 7 & $87,5 \%$ \\
\hline $\begin{array}{l}\text { Luxation of the elbow with rupture of the } \\
\text { proc. coronoideus }\end{array}$ & 6 & $75 \%$ \\
\hline $\begin{array}{l}\text { Luxation of the elbow without rupture of the } \\
\text { proc. coronoideus }\end{array}$ & 1 & $12,5 \%$ \\
\hline Injuries of the radial collateral ligament & 7 & $87,5 \%$ \\
\hline Injuries of the ulnar collateral ligament & 5 & $62,5 \%$ \\
\hline Injuries of the ventral capsula & 8 & $100 \%$ \\
\hline Fractures of the olecranon & 1 & $12,5 \%$ \\
\hline Monteggia-like lesions & 1 & $12,5 \%$ \\
\hline Essex-Lopresti-lesions & 0 & $0 \%$ \\
\hline
\end{tabular}

a contracture of the elbow with posteroradial instability and one case where the prosthesis inlay was broken. In both cases a second implantation became necessary. (Fig. 3a-b).

The rest of G2 showed a satisfying integration of the prosthesis. Neither a case of missing consolidation of the bone nor a case of humeroulnar arthrosis was documented. Subjective and functional outcome are shown in Table 5.

3/8 patients showed a highly limited range of motion posttraumatically, mainly concerning the pronation and supination. In two cases a lack of extension of $45^{\circ}$ was documented.

With these $3 / 8$ patients, early care training was started after an average of 4,67 days $(1 ; 1-12)$.

Furthermore, 3/8 patients suffered neurological damage including hyposensitivity of the fingers.

\section{Discussion}

Generally, there is a consensus to treat fractures of Mason type II with a dislocation of more than $2 \mathrm{~mm}$ and higher classified fractures operatively $(16,17)$. A challenge, not only due to the difficult operative treatment, but also due to the early functional mobilisation is a combination of dislocated fractures an instable joint.

In our study of treated radial head fractures we had one group which has been treated with an angular stable plate and another group treated with an endoprosthesis.

The best treatment for comminuted radial head fractures is still 
a)

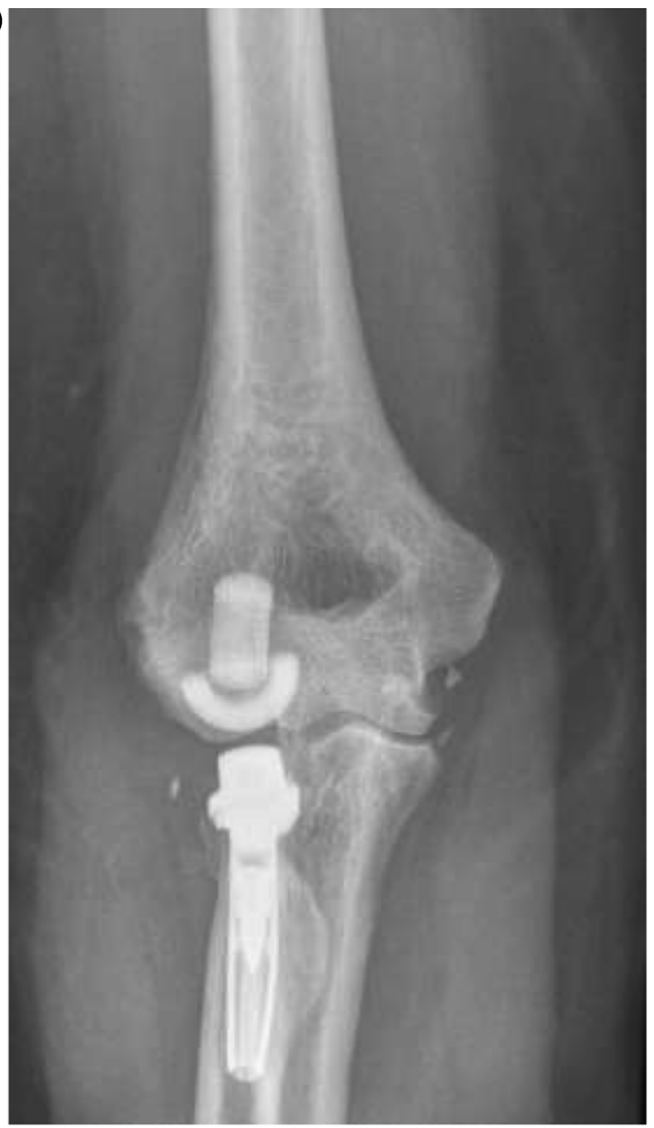

Figure 3. (a) X-ray a.p. MoPyc failure. (b) X-ray lateral MoPyc failure.

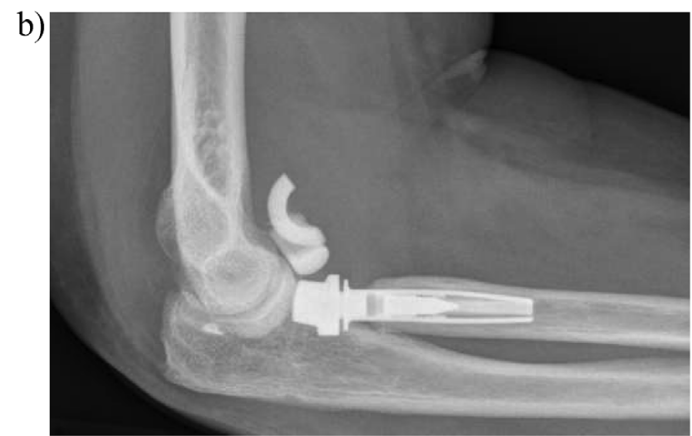

Figure 3. (continued)

discussed intensively by literature. Meanwhile it has become clear that the best therapy is determined decisively by the severity of the injury and by the existence of accompanying injuries. ${ }^{1,5,8,18}$

A broad agreement on the right treatment of simple radial head fractures without any accompanying injuries of the ligaments and without dislocation of the fragment already exists: conservative treatment. ${ }^{16,17}$

From a Mason-II-fracture with a dislocation $>2 \mathrm{~mm}$ on, the indication for an operative treatment is given. ${ }^{16,17}$

Possible operative treatments are resection of the radial head without replacement, replacement of the radial head with a prosthesis and ORIF ( $=$ open reduction and internal fixation).

Simple resection often leads to problems, therefore this treatment is only applied under exceptional circumstances nowadays, for example in case of an isolated radial head fracture without any accompanying injuries of the ligaments. ${ }^{19}$ Otherwise complications like osteonecrosis, pseudarthrosis or long-term limitations of the movement are to expect. $^{5,19}$

The replacement of the radial head with a prosthesis as well as the ORIF offer advantages over the simple resection and are therefore the main treatment options today.

The superiority of the reconstruction of the radial head over the resection without replacement could be shown by Lindenhovius et al. (2007). ${ }^{18}$

They reported a higher stability of the elbow joint and a reduced risk of humeroradial arthrosis.

Burkhart et al. (2015) have done follow-up examinations of 21 patients who were treated with angular stable plates (APTUS ${ }^{\circ} 2,0 \mathrm{~mm}$ proximal radius plates, Medartis ", Basel, Switzerland). The patients' follow-up examination was done after 12,1 months $^{5-23}$ on average and a lack of extension of $12,1^{\circ}\left(0-30^{\circ}\right)$, an average flexion of $136,7^{\circ}$ $\left(100-150^{\circ}\right)$, as well as a pronation and a supination of $70,9^{\circ}\left(40-80^{\circ}\right)$, respectively $63,3^{\circ}\left(20-80^{\circ}\right)$ was documented. ${ }^{20}$

In our study we observed a lack of extension of $12,7^{\circ}\left(10^{\circ} ; 0-30^{\circ}\right)$ and a flexion of $119^{\circ}\left(122^{\circ} ; 90-140^{\circ}\right)$, as well as a pronation and supination of $71^{\circ}\left(80^{\circ} ; 10-90^{\circ}\right)$, respectively $59,3^{\circ}\left(70^{\circ} ; 5-90^{\circ}\right)$.

Our results match the results of Burkhart et al. (2015) for the most part, only the flexion differs with $17,7^{\circ}$.

Burkhart et al. observed a partial radial head necrosis in one case. ${ }^{20}$ In our collective treated with angular stable plates, we observed 3 radial head necrosis; two of them were treated with a MoPyC-prosthesis and a radial head resection was performed in the third case, followed by the implantation of a Zimmer Coonrad/Morrey total elbow prosthesis.

The superiority of the implantation of the MoPyC-prosthesis over the resection without replacement was described by Hackl et al. ${ }^{21}$

They found that radial head prosthesis are superior to radial head resection in case of acute fractures that are not treatable with osteosynthesis, in order to reinsure the stability of the elbow joint.

Furthermore, they stated that correct implantation is technically difficult and finding the right height of the prosthesis is an elementary requirement to limit postoperative complications like instability, stiffness of the joint and the persistence of pain7,22.

In case of "overstuffing“, meaning an implantation of the prosthesis in a position too high, the result is an overload of the radial column of the wrist and the elbow, leading to early degeneration of the joints, even if the deprivations are little. ${ }^{20,23,24}$

Hackl et al. reported implant specific complications after MoPyCprosthesis implantation. $^{25}$

Amongst other things, one break of a prosthesis head, one break of a prosthesis neck and one disconnection of a prosthesis neck from the prosthesis head were described. These complications are rare, but they should still be considered when deciding for a treatment, as well as the fact that the implantation is technically very difficult. ${ }^{22,25}$

Our results show as well that the implantation is a challenging technique which needs an experienced surgeon and is afflicted with complications.

Because long-term data of the prosthetic treatment is barely existent and because the longevity of the prosthesis is unclear, reconstruction is the usually preferred treatment. ${ }^{19}, 26-28$

Sarris et al. ${ }^{29}$ documented that the ORIF should, if possible, always be the first choice in treatment planning and that the implantation of a prosthesis should only be considered if the possibility of ORIF is not given. $^{29}$

When comparing the results of both our collectives with each other, it can be noticed that no differences can be found regarding the agility. Both collectives reached a satisfying agility after the treatment, at most the supination movement shows a slight deficit within G1, namely $14,5^{\circ}$ less compared to G2.

Both collectives show satisfying results considering the strength of the affected elbow joint.

The aim of our study is to showcase the clinical outcome of both groups with an emphasis on possible persisting grievances and coping with daily living. 
The strength of our study is the detailed and considerable follow-up examination of our patients and the detailed documentation of our observations.

The main weakness of our study is the relatively limited number of patients, especially within G2, as well as the shortage of prospective data for comparison.

In our opinion, none of the treatments seems to be superior to the other at the moment, as both still lead to some complications and the postoperative outcome depends on the rate of accompanying injuries.

However, it seems possible to improve the outcome of G2 dramatically when preventing „overstuffing”, as well as „understuffing“.

Furthermore, it needs to be taken into consideration that mostly quite young patients suffer radial head fractures, which means patients would have to live with a prosthesis for years. At the moment, longterm data after prosthetical treatment are still missing.

\subsection{Conclusion for clinical practice}

Radial head fractures are traumatic injuries of the elbow joint, especially when occurring together with accompanying injuries.

To reach a satisfying long-term result, it is necessary to perform an accurate diagnosis and precise classification of the injury to find the best way of treatment. Furthermore, it is essential to restore the anatomical shape of the radial head as well as possible, respectively replacing it with a prosthesis, to prevent long-term damage like arthrosis of the elbow joint or a persisting limitation of movement and to ensure stability during an individually exercise as early as possible.

Both the treatment with angular stable plates and the implantation of radial head prostheses provide a clear benefit for the patients and predict promising results for the treatment of Mason-III- and MasonIV-fractures.

In our judgement, none of the treatments can be preferred in everyday practice at the moment.

The postoperative outcome is still dependent decisively on the extent of accompanying injuries and still needs to be improved.

\section{Conflicts of interest}

There is no conflict of interests according to the guidelines of the International Committee of Medical Journal Editors. The presentation of the topic is independent and the representation of the content is product-neutral.

\section{References}

1. Ambacher T, Maurer F, Weise K. [Treatment results after primary and secondary resection of the radial head]. Unfallchirurg. 2000;103(6):437-443.

2. Zimmermann G, Wagner C, Moghaddam A, Studier-Fischer S, Wentzensen A. Radiusköpfchenfraktur und Ellenbogenluxation. Trauma und Berufskrankheit. 2004;vol. 6(4):297-303 Springer-Verlag.

3. Duckworth AD, McQueen MM, Ring D. Fractures of the radial head. Bone Joint Lett J. 2013;95-B(2):151-159.
4. Zwingmann J, Welzel M, Dovi-Akue D, Schmal H, Sudkamp NP, Strohm PC. Clinical results after different operative treatment methods of radial head and neck fractures: a systematic review and meta-analysis of clinical outcome. Injury. 2013;44(11):1540-1550.

5. Röhm C, Lill H, Korner J, Josten C. Radial head fractures. Reconstruction, resection, replacement Trauma und Berufskrankheit. Supplement 1. Springer-Verlag; 2002:91-95.

6. Cobb TK, Beckenbaugh RD. Nonunion of the radial neck following fracture of the radial head and neck: case reports and a review of the literature. Orthopedics. 1998;21(3):364-368.

7. Ring D, Quintero J, Jupiter JB. Open reduction and internal fixation of fractures of the radial head. J Bone Joint Surg Am. 2002;84-A(10):1811-1815.

8. Raven TF, Banken L, Doll J, et al. Options and limits of angle stable plates in the treatment of comminuted radial head fractures. J Orthop. 2018;15(4):957-962.

9. Morrey B. The Elbow and its Disorders. Philadelpia: Saunders; 1993.

10. Radin E, Riseborough E. Fractures of the radial head. A review of eighty-eight cases and analysis of the indications for excision of the radial head and non-operative treatment. J Bone Joint Surg Am. 1966;48:1055-1064.

11. Mason ML. Some observations on fractures of the head of the radius with a review of one hundred cases. Br J Surg. 1954;42(172):123-132

12. Broberg M, Morrey B. Results of delayed excision of the radial head after fracture. $J$ Bone Jt. Surg. 1986;68:669-674.

13. Greenspan A. Skelettradiologie: Orthopädie, Traumatologie, Rheumatologie, Onkologie. 3 ed Urban \& Fischer Verlag/Elsevier GmbH; 2003:1118.

14. Hackl M, Burkhart KJ, Wegmann K, Hollinger B, Lichtenberg S, Muller LP. From radial head to radiocapitellar to total elbow replacement: a case report. Int $J$ Surg Case Rep. 2015;15:35-38.

15. Brooker AF, Bowerman JW, Robinson RA, Riley Jr LH. Ectopic ossification following total hip replacement: incidence and a method of classification. $J$ Bone Joint Surg Am. 1973;55(8):1629-1932 PMID: 4217797.

16. Akesson T, Herbertsson P, Josefsson PO, Hasserius R, Besjakov J, Karlsson MK. Primary nonoperative treatment of moderately displaced two-part fractures of the radial head. J Bone Joint Surg Am. 2006;88(9):1909-1914.

17. Tejwani NC, Mehta H. Fractures of the radial head and neck: current concepts in management. J Am Acad Orthop Surg. 2007;15(7):380-387.

18. Lindenhovius AL, Felsch Q, Doornberg JN, Ring D, Kloen P. Open reduction and internal fixation compared with excision for unstable displaced fractures of the radial head. J Hand Surg Am. 2007;32(5):630-636.

19. Rief H, Raven T, Lennert A, et al. Is Radial Head Resection after Trauma Still Considered up to Date. vol. 2. Obere Extremität Springer-Verlag; 2014:121-127.

20. Burkhart KJ, Gruszka D, Frohn S, et al. [Locking plate osteosynthesis of the radial head fractures : clinical and radiological results]. Unfallchirurg. 2015;118(11):949-956.

21. Hackl M, Wegmann K, Ries C, Leschinger T, Burkhart KJ, Muller L. [Radial head replacement - surgical technique and own clinical results]. Z für Orthop Unfallchirurgie. 2015;153(6):652-656.

22. Yian E, Steens W, Lingenfelter E, Schneeberger AG. Malpositioning of radial head prostheses: an in vitro study. J Shoulder Elb Surg. 2008;17(4):663-670.

23. Van Glabbeek F, Van Riet R, Baumfeld J. The kinematic importance of radial neck length in radial head replacement. Med Eng Phys. 2005;27:336-342.

24. Van Glabbeek F, Van Riet R, Baumfeld J. Detrimental effects of overstuffing or understuffing with a radial head replacement in the medial collateral-ligament deficient elbow. J Bone Joint Surg Am. 2004;86:2629-2635.

25. Hackl M, Wegmann K, Koslowsky TC, Zeifang F, Schoierer O, Muller LP. Rare implant-specific complications of the MoPyC radial head prosthesis. J Shoulder Elb Surg. 2017;26(5):830-837.

26. Moghaddam A, Lennert A, Studier-Fischer S, Wentzensen A, Zimmermann G. [Prosthesis after comminuted radial head fractures : midterm results]. Unfallchirurg. 2008;111(12):997-1004.

27. Ring D. Radial head fracture: open reduction-internal fixation or prosthetic replacement. J Shoulder Elb Surg. 2011;20(2 Suppl):S107-S112.

28. Moghaddam A, Raven T, Dremel E, Studier-Fischer S, Grutzner P, Biglari B. Outcome of radial head arthroplasty in comminuted radial head fractures: short and midterm results. Trauma Mon. 2016;21(1)

29. Sarris I, Kyrkos M, Galanis N, Papavasiliou K, Sayegh F, Kapetanos G. Radial head replacement with the MoPyC pyrocarbon prosthesis. J Shoulder Elb Surg. 2012;21(9):1222-1228. 